\title{
Divórcio dos pais: sentimentos e percepções das crianças
}

\section{Parents divorce: children's feelings and perceptions}

\author{
Camila Dias de Abreu', Liniker Douglas Lopes da Silva², \\ Luciana Maria da Silva ${ }^{3}$
}

Resumo

Nas últimas décadas têm-se observado o surgimento de novas configurações familiares, principalmente no início do século XXI, com reconhecimento da união estável, do divórcio e, consequentemente, o surgimento de famílias reconstituídas. Contudo, os processos de divórcios e/ou dissoluções conjugais acarretam consequências para o ex-casal e também para os filhos. Neste sentido, este estudo empírico e de abordagem qualitativa objetivou analisar as percepções e sentimentos das crianças acerca do divórcio dos pais, expressos por meio da construção de objetos lúdicos, durante o desenvolvimento de cinco "Oficinas de Crianças", do projeto de extensão "Oficinas de Parentalidade", em que participaram 22 crianças. Verificou-se que o brincar e os brinquedos auxiliaram na possível elaboração de sentimentos como raiva, medo de abandono e culpa, além de constatar as principais consequências advindas do divórcio e estratégias de enfrentamento utilizadas por estas crianças. Notou-se também que a "Oficina de Crianças" se revelou como um espaço acolhedor e fortalecido para a possível elaboração de tais vivências.

Palavras-chave: Parentalidade. Criança. Divórcio. Brinquedo. Psicanálise.

\begin{abstract}
In the last decades new family configurations have been observed, especially at the beginning of the 21 st century, with the recognition of stable union, divorce and, consequently, the emergence of reconstituted families. However, divorce and/or marital dissolution proceedings have consequences for the former couple as well as for their children. In this sense, this empirical and qualitative study aimed to analyze children's perceptions and feelings about their parents' divorce, expressed through the construction of playful objects, during the development of five "Children's Workshops" of the extension project "Parenting Workshops", in which 22 children participated. It was found that playing and toys helped in the possible elaboration of feelings such as anger, fear of abandonment and guilt, besides noting the main consequences of divorce and coping strategies used by these kids. It was also noted that the "Children's Workshop" proved to be a welcoming and strengthened space for the possible elaboration of such experiences.
\end{abstract}

Keywords: Parenting. Child. Divorce. Toy. Psychoanalysis.

\footnotetext{
${ }^{1}$ Graduação em Psicologia pela Universidade Federal do Triângulo Mineiro (UFTM), Minas Gerais, Brasil.

${ }^{2}$ Mestrado em Psicologia pelo Programa de Pós-graduação em Psicologia da Universidade Federal do Triângulo Mineiro, Minas Gerais, Brasil. E-mail: liniker08@hotmail.com

${ }^{3}$ Doutorado em Psicobiologia pela Universidade de São Paulo (USP), São Paulo, Brasil. Professora do Departamento de Saúde Coletiva da Universidade Federal do Triângulo Mineiro, Minas Gerais, Brasil.
} 


\section{Introdução}

Nas últimas décadas têm-se observado o surgimento de novas configurações familiares, principalmente no início do século XXI, e neste contexto pode ser citado o reconhecimento da união estável, o divórcio e, consequentemente, o surgimento de famílias reconstituídas. No entanto, tais mudanças fizeram com que viesse à tona uma discussão delicada: como ficam as crianças no que diz respeito aos pais separados e às difíceis disputas judiciais? (FERREIRA, 2015). Pode acontecer de nessas disputas relacionadas tanto ao divórcio em si quanto à regulamentação da guarda dos filhos, ou em outras situações de conflitos familiares, que os genitores que por algum motivo não conseguem vivenciar estes momentos de maneira saudável, deixem transbordar para seus filhos, sejam crianças e/ou adolescentes, sentimentos de vingança e desmoralização da outra parte, prejudicando-os (BORDONI; TONET, 2016).

Neste sentido, a construção da relação entre pais e filhos e a manutenção do vínculo parental pós-divórcio irá depender da motivação do ex-casal em diferenciar conjugalidade de parentalidade. Conjugalidade se refere à relação entre duas pessoas, casadas ou não, que se relacionam pensando em construir uma família sem necessariamente ter filhos. Uma das características das relações conjugais diz respeito à dissolubilidade que pode ocorrer pelo divórcio ou dissolução da união estável. Já no que tange à parentalidade, esta não pode de forma alguma ser desfeita, diz respeito à relação existente entre pais e filhos e que não termina com o divórcio do casal (OLIVEIRA; CREPALDI, 2018; SCHNEEBELI; MENANDRO, 2014).

A Convenção dos Direitos da Criança, promulgada pelo Decreto n. ${ }^{\circ} 99.710$, de 21 de novembro de 1990, prevê que a criança que tenha pais separados tem por direito manter relações pessoais e contato direto com ambos, exceto se for contrário ao interesse da criança. Esta convenção apresentou o princípio do melhor interesse da criança, significando que seus desejos devem ser prioridade do Estado, sociedade e família, especialmente quando se diz sobre as relações familiares (BORDONI; TONET, 2016).

Tal princípio se fundamenta no Art. 227 da Constituição Federal de 1988 que diz que é dever da família, sociedade e Estado garantir à criança e ao adolescente o direito à convivência familiar e comunitária, à saúde, à dignidade, ao respeito, à educação, ao lazer, à liberdade, à alimentação, à cultura, à profissionalização e a salvo de qualquer forma de negligência, opressão, exploração, discriminação, violência e crueldade (BORDONI; TONET, 2016), também garantidos pelo Estatuto da Criança e da Adolescência (1990). A necessidade de uma legislação em favor da criança e do adolescente nasce do cuidado em lidar com as repercussões da dissolução conjugal de uma forma mais rigorosa, objetivando a diminuição de conflitos familiares e, principalmente, a prática da alienação parental, procurando desta maneira evitar possíveis traumas que possam surgir e tentando preservar ao máximo a boa convivência familiar em prol da criança/ adolescente (BORDONI; TONET, 2016).

A alienação parental pode ser entendida como a aversão que o filho passa a demonstrar ter por um de seus genitores sendo influenciado pelo outro genitor, ou seja, um dos pais manipula os sentimentos do filho com relação ao outro e pode criar obstáculos que dificultam a prática da parentalidade por parte do outro cônjuge (SANTOS, 2013). Este é considerado um assunto delicado principalmente pelas consequências que gera, sendo por isso considerado pela Lei n. ${ }^{\circ} 12.318$, de 26 de agosto de 2010, uma forma de abuso moral pelas consequências que traz ao desenvolvimento psicológico e emocional dos afetados e, além disso, por interferir diretamente no convívio familiar dos filhos (BORDONI; TONET, 2016).

Diante do exposto, considera-se de extrema importância que espaços de diálogo e reflexão acerca da experiência do divórcio vivenciada por pais e filhos sejam pensados na prática, proporcionando dessa forma o desenrolar de ações com capacidade de auxiliar os membros envolvidos a minimizar conflitos e situações negativas advindas desse 
processo, como, por exemplo, as Oficinas de Pais e Filhos, as quais vêm se mostrando fundamentais para a possível manutenção do bom convívio familiar pós-divórcio (BORDONI; TONET, 2016). Estas oficinas possuem a função de despertar a atenção dos ex-cônjuges sobre a forma como estão desempenhando a parentalidade pós-divórcio para com seus filhos, levando-os a refletir sobre suas ações. Além disso, buscam trabalhar a maneira como estes pais enfrentam o processo de divórcio e a vivência dos filhos, tentando minimizar o impacto da dissolução conjugal e suas consequências (BORDONI; TONET, 2016; SILVA et al., 2015).

Pensando nisso, foi implantado um projeto de extensão intitulado "Oficinas de Parentalidade" que se constitui em uma parceria entre uma universidade de uma cidade do interior de Minas Gerais e uma das Promotorias da Comarca local, tendo seu início em setembro de 2014. Com o intuito de favorecer práticas saudáveis em benefício de famílias que estão vivenciando processos de divórcio, disputas de guarda e outros processos judiciais conflituosos, e recomendado pelo Conselho Nacional de Justiça (CNJ) como uma política pública para resolução de conflitos desta natureza, caracteriza-se como a segunda experiência de implantação do projeto em Minas Gerais e a primeira no interior do Estado (SILVA et al., 2015).

O principal objetivo do projeto é apoiar famílias para que possam compreender os sentimentos que perpassam os filhos que vivenciam o processo de divórcio dos pais, a fim de que consigam adquirir suporte necessário para promover ações de mudanças visando o bom enfrentamento da situação. Para isso, procurase oferecer, por meio de oficinas para pais, adolescentes de doze a dezessete anos e crianças de seis a onze anos, o aparato necessário para que o menor dano possível seja acometido nos envolvidos (SILVA et al., 2015).

A "Oficina de Crianças", foco principal da presente pesquisa, ocorre dentro das "Oficinas de Parentalidade" e possui como intuito a discussão de temas relacionados com a separação dos pais expostos de forma lúdica e adaptados ao universo infantil. Nela são contadas histórias, realizadas dinâmicas, brincadeiras, desenhos e, ao final, é realizada a atividade "Oficina de Sucatas", a qual oferece para a criança um espaço seguro para expressar seus sentimentos. A "Oficina de Sucatas" é o momento no qual as crianças constroem objetos com materiais recicláveis e, logo depois, há uma roda de conversa em que estas contam do objeto construído e do seu significado, possibilitando a discussão sobre a transformação de uma situação ruim em boa, pois se traz a perspectiva de algo que seria lixo poder ser construído em algo com significado (SILVA et al., 2015).

Nesse sentido, reflete-se acerca da função do brinquedo e do brincar para as crianças, pois estes se tornam facilitadores de acesso ao seu mundo interno, o que, para Melanie Klein, acaba por trazer a criança para o centro do processo psicanalítico, considerando que o brinquedo irá ocupar um espaço de extrema relevância, pois possibilita trazer à tona o não-dito por ela (SOUSA; ANDRADE; ANDRADE, 2016). É brincando que a criança consegue projetar seus conteúdos de ansiedade acerca de suas experiências traumáticas, possibilitando, desta forma, a elaboração destes que estão alocados internamente. $\mathrm{O}$ brinquedo nestes casos age como uma ponte, uma forma de possibilitar a comunicação, oferecendo a chance de relacionar seu mundo interno com o externo (SILVA, 2015). É por meio de brincadeiras e jogos que a criança expressa suas fantasias, seus desejos e suas experiências reais de uma forma simbólica (KLEIN, 1997).

De acordo com Santos (2013), compreender o sofrimento no qual a criança se encontra em situações referentes ao divórcio dos pais e/ou disputa de guarda permite que recursos para a auxiliar em seu enfrentamento dessas vivências possam ser pensados, podendo minimizar, assim, a probabilidade de aumentar o sofrimento, bem como suas angústias e consequências emocionais diante destas situações.

Em consonância, vários estudos falam sobre a visão dos filhos sobre o divórcio dos pais, as consequências desse processo em suas vidas e também sobre a importância do brincar para auxiliar 
as crianças na expressão dos seus sentimentos (SANTOS, 2013; SANTOS, 2014; SILVA, 2015). Entretanto, lacunas foram encontradas a respeito da análise e compreensão da maneira como as crianças vivenciam e expressam através do lúdico o processo de divórcio dos pais, principalmente no âmbito das "Oficinas de Parentalidade". Por ser uma proposta recente, há necessidade de estudos sobre seus efeitos junto às crianças, a fim de alicerçar a importância da expansão das implementações das mesmas no Brasil, como recomenda o CNJ.

Diante disso, o presente estudo teve por objetivo analisar as percepções e sentimentos de crianças acerca do divórcio dos pais expressos por meio da construção de objetos lúdicos. Para isso buscou-se compreender sentimentos e percepções das crianças participantes sobre a separação dos pais, avaliando as consequências e estratégias de enfrentamento utilizadas por elas diante da vivência deste processo, através da construção de objetos lúdicos produzidos nas "Oficinas de Crianças" do projeto "Oficinas de Parentalidade".

\section{Método}

\section{Tipo de estudo}

Trata-se de um estudo empírico de abordagem qualitativa, descritivo e de caráter exploratório. Turato (2011) salienta que os estudos qualitativos detêm interesse em conhecer os significados e sentidos atribuídos a determinados fenômenos pelos indivíduos que os vivenciam.

$\mathrm{O}$ instrumento utilizado para o estudo foi um diário de campo no qual foram registrados os relatos trazidos pelas crianças acerca das vivências advindas do processo de divórcio dos pais durante o desenvolvimento das atividades realizadas na "Oficina de Crianças", bem como a descrição das construções dos objetos confeccionados durante as "Oficinas de Sucatas". De acordo com Afonso et al. (2015), o diário de campo propicia aos pesquisadores a descrição de pessoas, objetos, conversas, lugares, situações, assim como suas ideias, estratégias e reflexões acerca do assunto pesquisado.

\section{Participantes}

A pesquisa foi realizada com cinco grupos de crianças compostos por filhos de pais em processo de divórcio e/ou disputa de guarda, com idade entre seis e onze anos, participantes das "Oficinas de Parentalidade", totalizando 22 crianças. Os grupos ocorreram em encontro único mensal, sendo que a cada mês novos participantes integravam a "Oficina de Crianças".

\section{Procedimento de coleta e análise dos dados}

A coleta dos dados ocorreu durante a realização das atividades do projeto de extensão intitulado "Oficinas de Parentalidade", realizado mensalmente em uma universidade do interior de Minas Gerais, no período de outubro de 2017 a maio de 2018.

As famílias que se encontravam em processos judiciais foram previamente convidadas a participar das oficinas pelas três Varas de Família existentes no município. Todas foram acolhidas pela equipe e encaminhadas para as salas referentes a cada tipo de oficina, sendo duas destinadas aos pais (a fim de separar os genitores), uma destinada às crianças e outra aos adolescentes. As oficinas têm duração de quatro horas e na metade do tempo ocorre uma breve pausa para um lanche coletivo. O lanche para os grupos de pais é dividido em dois momentos separados, porém os filhos participam desses dois momentos do lanche para que possam se reunir com os dois genitores. O material disponibilizado para sua execução é fornecido pelo CNJ e são ministradas por instrutores previamente capacitados (SILVA et al., 2015).

A "Oficina de Crianças", principal foco desta pesquisa, é organizada por várias atividades. Inicialmente tem-se a dinâmica de apresentação e interação, depois a narração da história "O melhor dos dois ninhos" (CLARKE, 2012), que conta sobre uma cegonha filhote que vivencia a separação dos pais e precisa se adaptar à nova fase. Depois há a confecção do desenho da família, com pausa para o lanche em seguida. Ao final ocorre a "Oficina de 
Sucatas", momento em que as crianças constroem objetos a partir de material reciclável. O material ofertado para esta atividade é composto de produtos limpos, longe de possíveis riscos de acidentes e são variados, como caixas de sucos e leite, rolos de papel, fita crepe, garrafas PET, molas, pedaços de isopor e outros, como tesoura sem ponta, cola não tóxica, fita adesiva colorida, canetinhas, lápis de cor, papel colorido, dentre outros.

Ao final da "Oficina de Sucatas", após a construção dos objetos, é realizado um círculo no chão em que as crianças conversam sobre suas construções, contando o que produziram, suas funções, significados, nomes. As crianças podem optar por levar seus objetos para casa, assim como os desenhos produzidos durante a oficina. Todas ganham o gibi com a história "Turminha do Enzo: meus pais não moram mais juntos. E agora?" (CONSELHO NACIONAL DE JUSTIÇA, 2015), que narra a história de quando Enzo recebe a notícia da separação dos pais, os sentimentos que vivencia nesse momento e compartilha com amigos. Durante o desenvolvimento de todas as oficinas, a pesquisadora participou com as crianças, interagindo em vários momentos e facilitando a construção de um vínculo mínimo para aquele momento.

Importantedestacarquea "Oficinade Sucatas" oferece a oportunidade para que, a partir de uma atividade concreta, a criança tenha a possibilidade de simbolizar a nova constituição familiar, além de ter como principal objetivo trabalhar o conceito de transformação, desenvolvendo a partir do trabalho com recicláveis a chance de ressignificar as relações familiares (CONSELHO NACIONAL DE JUSTIÇA, 2016).

$\mathrm{O}$ diário de campo referente às oficinas contendo as falas das crianças e seus comportamentos expressos no decorrer das atividades, juntamente com a descrição dos objetos construídos na "Oficina de Sucatas", foi analisado a partir da técnica da análise de conteúdo. Segundo Bardin (2011), esta técnica se caracteriza por ser um grupo de instrumentos metodológicos em constante mudança podendo ser usados para conteúdos diversificados.
A análise de conteúdo é uma maneira que permite a análise das comunicações que irá explorar as falas dos participantes da pesquisa, bem como a observação do pesquisador. Procurase classificar os dados coletados dentro deste método em temas ou categorias que possam ajudar na compreensão do que está por trás do que foi falado (SILVA; FOSSÁ, 2015).

A partir da análise, três eixos temáticos foram suscitados e discutidos sob o referencial psicanalítico apoiado em Melanie Klein, por exemplo, e em outros autores que abordam temas relacionados ao divórcio, parentalidade e família, como Féres-Carneiro e Magalhães (2011) e Santos (2014).

\section{Considerações éticas}

A pesquisa foi aprovada pelo Comitê de Ética em Pesquisa (CEP) da universidade onde ocorreu o estudo sob o parecer 2.431.753. Além disso, foram adotados nomes de estrelas para as crianças participantes, a fim de se preservar suas identidades.

\section{Resultados e Discussão}

Eixo 1 - Sentimentos e percepções de crianças sobre a separação dos pais

A qualidade da relação estabelecida entre os pais de uma criança acaba por afetar diretamente sua saúde mental. Se considerarmos que esta criança cresce em um ambiente onde o casal esteja em conflito constante, pode ser que absorva para si não só o sofrimento que os perpassa, como também as brigas e comportamentos agressivos sem, muitas vezes, ter ideia do motivo de tais situações estarem acontecendo. Este tipo de vivência pode gerar diversos sentimentos nas crianças e, possivelmente, afetar seu desenvolvimento social e emocional causando traumas para a vida toda (CRUZ et al., 2013). Tais situações podem ser encontradas na presente pesquisa em que Antares (6 anos) relata "Meu pai e minha mãe briga todo 
dia de dia e de noite [...] eu tô muito triste e tô muito chateado", demonstrando durante toda a oficina comportamentos agressivos, refletindo a maneira com que percebe a relação de seus pais e reproduzindo tais comportamentos em sua própria relação com os outros. Tal fato pode ser observado ainda por meio da construção de seu objeto na "Oficina de Sucatas", uma arma, e ao brincar com ela, apontava para a cabeça de outras crianças fingindo estar atirando; outras vezes apontava para o teto ou para a parede e, quando não fazia isso, rolava pelo chão como se estivesse em um campo de batalhas fugindo de tiros.

Essas situações poderiam ter fim com a ruptura dos laços do casamento, porém, em pesquisa realizada por Brito (2007), foi constatado que com o fim da união do casal, a ideia de que as brigas também teriam fim geralmente não condiz com a realidade. Normalmente, dentro desses conflitos há uma mistura de sentimentos que afetam tanto o casal, como raiva e tristeza, quanto as próprias crianças, como solidão, insegurança, medo e culpa (CRUZ et al., 2013). Foi o que aconteceu com Hadar (7 anos), que relatou estar se sentindo solitário e sofrendo com a falta do pai, e Alya (9 anos) que disse "A gente fica com peso na consciência quando eles brigam".

Féres-Carneiro e Magalhães (2011) observam que há diferença na visão masculina e feminina sobre os filhos após o divórcio. Esta diferença aparenta ser pelo fato de que, geralmente, os filhos ficam com as mães, sendo que os pais se mantêm afastados deste convívio, gerando maior sofrimento nas crianças devido a suas ausências. Isto pode colaborar para que, de certa forma, estes pais projetem nelas sentimentos negativos vivenciados em decorrência do divórcio, além de poder gerar um distanciamento da família extensa, como, por exemplo, dos avós paternos (BRITO, 2007). Esta situação pode ser ilustrada com a fala de Kuma (11 anos) quando diz: "Eu vejo pouco meu pai [...] de 15 em 15, aí a gente vai na minha vó, mãe dele, mas eu vejo ela pouco também porque só ele me leva lá, eu gosto muito dela".
No entanto, quando se compara com Mira (6 anos) dizendo que, apesar de seus pais brigarem muito, ela vê bastante o pai, percebese com isso que, apesar de sua ausência em casa, este não deixou que o distanciamento natural deste momento prejudicasse a relação entre eles. Além disso, Mira ilustrou muito bem esta situação na "Oficina de Sucatas" ao construir um telefone sem fio para conversar com seu pai, fato observado na construção de outras crianças também como Atria (9 anos) e Sirius (7 anos). As situações acima confirmam o que Cruz et al. (2013) dizem quando afirmam que não é apenas o divórcio que gera consequências na família e que a separação terá chances de ser melhor compreendida pelas crianças quando seus pais conseguirem administrá-la de forma saudável, fazendo com que seus filhos entendam que, apesar de não estarem mais juntos, pai e mãe continuam exercendo suas funções.

Nota-se, também, a fantasia de que o Poder Judiciário está incumbido de solucionar os impasses que permeiam a dissolução conjugal e sanar os conflitos familiares (ARPINI; CÚNICO; ALVES, 2016). Essa questão é vista nas falas de Naos (6 anos), "O juiz falou que a gente pode ver meu pai de 15 dias"; de Regor (9 anos), "Foi o juiz que mandou eu vim aqui hoje"; e de Sol (7 anos), quando diz "Hoje é o dia dele, do meu pai". Tais situações demonstram que a falta de empoderamento familiar nas questões do divórcio e disputas judiciais podem afetar a percepção das crianças acerca da função familiar e da parentalidade, podendo prejudicar a identificação destas com os objetos parentais, gerando consequências para seu desenvolvimento psíquico (LEITE; OLIVEIRA NETA, 2016).

Ao entenderem que há muitas mudanças advindas desse momento, as crianças percebem que a principal delas está relacionada com o fato de que agora possuem duas casas, o que pode favorecer ou não a compreensão do sentimento de que, mesmo separados, pertencem tanto ao mundo do pai quanto ao da mãe (BRITO, 2007). No entanto, conforme foi observado na fala de Hadar (7 anos), 
"Eu tô morando em quatro ninhos ${ }^{4}$, com minha irmã, mãe, pai e avó. Essa história é que nem eu", percebe-se que não conseguiu fazer a atividade do Desenho da Família, desenhando apenas um coração com ajuda de uma extensionista enquanto falava coisas como "não consigo desenhar [...]". Nota-se que essas crianças podem perder a referência de lar, pois, a partir do momento em que os pais se separam, elas passam a ter mais de um, podendo dificultar a compreensão de que ainda assim pai e mãe continuarão exercendo suas funções, mesmo em casas separadas.

Pensando nas várias percepções que as crianças demonstraram ter acerca do divórcio dos pais, compreende-se que há momentos em que entendem que é melhor que estes fiquem separados como em pesquisa desenvolvida por Azambuja, Larratéa e Filipouski (2009), em que as crianças relatam terem percebido com o passar do tempo que a confiança e o estabelecimento da nova rotina permitiram que o impacto emocional do primeiro momento fosse ocupado pelas novas formas de adaptação, reduzindo assim as ansiedades advindas do processo de divórcio. Tal percepção foi observada na fala de Chow (9 anos) sobre o divórcio de seus pais - "Hoje em dia eles não brigam mais [...]" -, podendo ser esta uma possível forma de enfrentamento encontrada por elas para lidar com este novo contexto de vida (SANTOS, 2014). Desta forma, percebeu-se a importância de verificar quais são os tipos de enfrentamento que estas crianças utilizam para lidar com o processo de divórcio dos pais.

\section{Eixo 2 - Estratégias de enfrentamento das crianças frente ao divórcio dos pais}

Para conseguir vivenciar momentos de crise e minimizar sentimentos negativos, muitas crianças fazem uso de mecanismos de defesa e estratégias de enfrentamento a fim de lidar com tais situações como o processo de divórcio dos pais (AZAMBUJA; LARRATÉA; FILIPOUSKI, 2009). Nas circunstâncias em que estas podem brincar de forma coletiva, como nas "Oficinas de Parentalidade", lhes são permitidas vivenciar situações que nem sempre são reais, deixando-as livres para expressar os sentimentos do modo como desejarem, facilitando, dessa forma, o processo de significação a partir de ideias, concepções, valores e expectativas de exercerem determinados papéis naquela brincadeira (PEREIRA; LIRA; PEDROSA, 2011).

Neste ínterim, a atividade "Oficina de Sucatas", em que há a possibilidade da construção de um objeto qualquer por meio de materiais recicláveis, permite que tanto na confecção, quanto nas brincadeiras com os objetos revelem significados para as crianças, como observado na brincadeira de Navi (9 anos) com seu "megafone". Navi se destacou em uma das oficinas pela sua maneira extremamente agitada e, por vezes, agressiva de não só brincar com sua construção, mas também ao lidar com os temas abordados durante o desenvolvimento de todas as atividades. Ao final da oficina, imitava um cachorro bravo, depois um lobo uivando e sempre fazia os sons nos ouvidos das outras crianças ali presentes, perturbando-as. Quando lhe foi solicitada a descrição do objeto, disse "as pessoas precisam saber como ele grita alto", como se quisesse fazer com que as pessoas ouvissem seu grito de socorro.

Melanie Klein foi quem criou a técnica de analisar o mundo psíquico infantil por meio de atividades lúdicas. O brincar, para ela, foi considerado uma atividade natural das crianças, sendo, então, uma forma destas conseguirem expressar de maneira simbólica suas fantasias inconscientes. O principal elemento do modo de pensar para Klein é a existência da fantasia e do que ela chamou de "objetos internos" acerca das vivências que são desenvolvidas no contato que a criança tem com a realidade externa. Portanto,

\footnotetext{
${ }^{4}$ Fazendo menção à história em quadrinhos "O melhor dos dois ninhos", contada para as crianças como parte das atividades proporcionadas pela Oficina.
} 
para esta autora, o método do brincar para as crianças é aquele que terá o mesmo significado das associações livres na psicanálise dos adultos (COSTA, 2008).

Para Klein, é neste momento que está presente a chance de proporcionar para a criança a mudança daquilo que foi vivenciado passivamente para um modo ativo, ter o domínio sobre sua realidade, repetir experiências traumáticas com a possibilidade de ser elaborada, entendendo, portanto que há aí o trabalho de elaboração, exploração e modificação das angústias (SOUZA, 2008b), como verificado nas experiências com as crianças participantes das oficinas.

Em 1946, esta autora demonstrou como parte de sua teoria o conceito de "identificação projetiva", expondo que a projeção se dá para dentro do objeto de forma que sua identidade possa ser modificada, auxiliando no desenvolvimento da capacidade de significar a experiência emocional (SOUZA, 2008a; SOUZA, 2012). Tal fato pode ser ilustrado por Rana (7 anos), que construiu um robô chamado João, mesmo nome do irmão, mas depois mudou para Lucas. Enquanto relatava que a cabeça do robô estava escondida e que ele estava "dodói” (sic), sangrando, havia cola escorrendo dentro da garrafa simbolizando o sangue do robô, tendo colocado uma "faixa" na frente de onde estava sua cabeça dizendo que era para esconder seu rosto. Ao mesmo tempo narrava o episódio em que seu irmão chorou no momento do lanche coletivo das "Oficinas de Parentalidade", mas não sabe o motivo, deixando clara a projeção que fez de seu irmão com o robô, tentando, por meio daquela construção, "curar" o dodói do irmão, uma vez que em seu mundo real não consegue, possivelmente, encontrar um meio para elaborar a angústia de estar vivenciando aquela situação.

$\mathrm{O}$ mesmo caso referente à projeção das crianças nos objetos construídos pode ser encontrado também em outros exemplos como o de Sol (7 anos), que ao construir um lançador de bombas que atira bombas nas pessoas, disse "atiro bombas nas pessoas porque assim elas não me atingem", apresentando, além da projeção, uma necessidade de defesa. Tal aspecto foi observado também na construção de Regor ( 9 anos) que confeccionou uma pipa, mesmo objeto que aparece na história "O melhor dos dois ninhos" (CLARKE, 2012) e um tanque de guerra com uma bala dentro dizendo que está se preparando para entrar em uma batalha, claramente projetando nele o momento que está vivendo de entrar na batalha do processo de separação dos pais. Temse, também, Menkar (11 anos), que construiu um soldado de guerra, claramente projetando ali a imagem do pai que batalha na justiça contra a mãe para não separar os irmãos maiores dos menores.

Além disso, nas outras formas de enfrentamento encontradas por estas crianças, destaca-se a relação do fortalecimento entre os irmãos, considerando que não é apenas quando um filho sai de casa que os pais experimentam a "Síndrome do Ninho Vazio", os irmãos também enfrentam esta síndrome. O irmão "que fica" acaba vivenciando sentimentos de tristeza, solidão e abandono quando seus outros irmãos saem de casa, sendo tais sentimentos agravados quando a proximidade entre estes é elevada (GOLDSMID; FÉRES-CARNEIRO, 2011). Tal fato pode ser ilustrado pela fala de Menkar (11 anos): "[...] só que meu pai não queria separar os irmãos, mas a minha mãe não quer a guarda dos maiores, que é eu, a Lucida e o outro, só quer a guarda dos menor (sic), que é o Hadir e o Sham que já tá com ela"; e pela construção de Sirius ( 7 anos), que ao fazer um carro, relatou que quem vai dirigir é seu irmão mais velho e que irão passear nele junto com sua outra irmã, apenas os três.

Vale ressaltar que o vínculo construído entre os irmãos acaba por favorecer a ajuda necessária para lidar com situações de crise como a separação dos pais, sendo que estas podem, não necessariamente, desenvolver algum tipo de patologia nos afetados, por isso é importante considerar que o apoio nesse momento seja fortalecido (GOLDSMID; FÉRES-CARNEIRO, 2011). Nesse sentido, as "Oficinas de Crianças" podem funcionar como um espaço protegido 
para este fortalecimento como observado na fala de Sham (6 anos) durante uma das atividades, quando perguntou para todos "Quem gosta de mim?" e seu irmão Hadir (7 anos) respondeu "Quem gosta dele é eu, a Lucida e o Menkar, porque a gente é irmão".

Pensando nisso, a dependência materna e paterna para a constituição psíquica do ser humano é incontestável, porém a dependência afetiva, não vinda apenas de pai e mãe, também se torna indispensável. Nesse sentido, a família se configura como um importante espaço de amparo e afeto, em que estas funções irão se completar, tendo cada membro uma função. Tais papéis não precisam necessariamente estar conectados de forma biológica para isso, sendo assim, a criança pode determinar que outra figura parental exerça as funções da figura materna ou paterna, como, por exemplo, avós e tios (GRIGORIEFF; NÜSKE, 2015). Este fato foi encontrado em alguns casos da oficina em que os filhos dos pais separados ficam com os avós, como Botein (6 anos) e Sarir (7 anos), ambos residem com os avós após o divórcio dos pais possivelmente por buscarem a necessidade de se ter uma figura parental segura que auxilie seu desenvolvimento, pois, com a separação, as figuras dos genitores podem estar prejudicadas internamente.

Nesse sentido, a família se constitui como um lugar importante para a criança que está em formação psíquica, exercendo a função de ser um ambiente que auxilia tal formação por meio do afeto e do cuidado. Entretanto, após o divórcio dos pais, dependendo da forma como estes irão lidar com tal situação, por consequência ocorre um afastamento materno-paterno filial podendo ser classificado também como abandono afetivo (GRIGORIEFF; NÜSKE, 2015). Esta se caracteriza como sendo uma importante consequência observada nos casos em que há divórcio dos pais e vista também nas crianças que participaram da presente pesquisa, por isso, identificou-se a necessidade de analisar quais as consequências que a separação dos pais acarreta na vida das crianças.

\section{Eixo 3 - Consequências do divórcio}

na vida das crianças

O divórcio pode acarretar consequências não apenas para o ex-casal como também para as crianças envolvidas e entre estas pode ser citada a regressão, que em seu sentido temporal seria a volta do sujeito para etapas já vivenciadas de seu desenvolvimento (LAPLANCHE; PONTALIS, 2016), o que foi observado no caso de Hadir (7 anos), que apresentou uma fala bastante infantilizada, até mesmo em seu tom de voz e nas pronúncias de palavras erradas, aparentando ser uma criança menor do que a de sua idade.

A agressividade foi evidenciada na maioria das crianças que participaram das oficinas analisadas pela presente pesquisa e além de comportamentos agressivos durante o desenvolvimento das atividades não só consigo mesmos, mas também com as outras crianças que participavam. Tal evidência pode ser comprovada a partir da construção das sucatas, como nos casos de Miram (7 anos), que fez um estilingue, e de Botein (6 anos), que construiu um robô chamado Bill, que atirava mísseis pelos braços, deixando claro nesse momento sentimentos de ataque e defesa ao dizer que com as sucatas " $d a ́$ pra construir armadura pra gente mesmo". As construções de robôs se destacaram e nota-se que geralmente estão relacionados à agressividade, como observado nos casos de Sirius (7 anos), que ao construir um robô disse que atira "coisas" pelos braços e essas coisas atingem as pessoas; a construção de Sol (7 anos), um lançador de bombas que atira bombas nas pessoas; a cobra de Kaus (11 anos); o tanque de guerra com uma bala dentro, de Regor (9 anos); além de robôs que não possuem nomes e não "fazem nada" como os de Hadar (7 anos), de Merak ( 9 anos) e Sarir (7 anos).

Como se tem notado, não são poucas as consequências da separação dos pais para a vida e desenvolvimento dos filhos, entretanto há ainda uma problemática maior que pode comprometer ainda mais tais consequências, sendo esta a alienação parental que se caracteriza por ser um 
processo de descrédito do ex-cônjuge com o intuito de gerar na criança sentimentos negativos ao outro genitor (FERREIRA, 2015). Tem-se a noção de que a alienação se dá somente quando há $\mathrm{o}$ ataque contra o outro genitor, no entanto, com a fala de Lucida (10 anos) pode-se perceber que nem sempre é o que acontece " $A$ minha mãe mandava a gente xingar a nossa madrasta de gorda, porque ela era meio gordinha sabe, ai ela ficava falando pra gente chamar ela de baleia e ai teve uma vez que quando a gente fez isso nosso pai colocou a gente de castigo, dai quando a gente contou pra ela, ela brigou com o pai falando que não era pra gente ficar de castigo por causa de piranha".

Pensando nisso, o afeto é um dos principais elementos na vida das pessoas e sua falta pode fazer surgir consequências negativas, como distúrbios psicológicos, insegurança e complexo de inferioridade, principalmente nas crianças que ainda estão em desenvolvimento. Normalmente durante a relação conjugal, os filhos tendem a receber atenção e afeto de ambos os pais, entretanto, no momento da separação do casal, tal cuidado tende a ficar ausente por um dos genitores podendo resultar no chamado abandono afetivo (COSTA; GOMES, 2017). Este se caracteriza como o afastamento ou ausência afetiva de um ou ambos os pais no convívio com seus filhos, principalmente após o divórcio, por razões conscientes ou inconscientes. Muitas vezes acontece deste fato ser mais causado pelos pais das crianças, podendo ser justificado por ser eles aqueles que saem de casa após a separação (BRAGA; FUKS, 2013). Este tipo de sentimento foi vivenciado por Sol (7 anos) no momento do divórcio de seus pais, "Eu achei que meu pai nunca mais ia me ver, mas ele foi e eu fiquei muito feliz", contrastando com o caso de Sirius (7 anos), cujo pai o abandonou completamente após uma briga grave com a mãe, presenciada por Sirius e sua irmã. Sirius sabe de sua existência e que seu pai inclusive reside com seu irmão mais velho, no entanto, se nega a vê-lo como aconteceu no dia em que participou da oficina e que seu pai também estava lá.
Nesse sentido, há de se refletir acerca não somente das motivações que levam o pai a abandonar o filho, mas também, sobre as causas que acarretam o não desejo dos filhos em manter a relação afetiva com um dos genitores. Devese ir além, como nos casos em que a vontade de não haver contato entre pai e filho não é atendida, geralmente definida em processo judiciário na obrigação da convivência, como bem ilustrado por Kuma (11 anos), quando, ao se negar a viajar com o pai ou dormir em sua casa, ouve que "agora é obrigado a ir [...]", por ter sido determinado após o processo do divórcio ter sido aberto na justiça. Deve-se refletir, portanto, que quando o afeto se faz presente há o desejo da convivência, que merece ser reconhecido e fortalecido pelo Estado. No entanto, este não pode ser transformado em dever de convivência quando não há tal sentimento. Este afeto, o cuidado, o querer genuíno somente irão existir quando o desejo for despertado pelos dois sujeitos que estão vivenciando tais situações e não determinado por um outro (BRAGA; FUKS, 2013).

\section{Conclusão}

Os sentimentos e percepções verificados nesta pesquisa com crianças em processo de divórcio dos pais e outros conflitos judiciais variaram entre raiva, tristeza, medo de abandono e culpa. Dependendo da maneira com que os pais lidam com a situação, sentimentos e comportamentos agressivos foram reproduzidos pelos filhos, como constatado em alguns casos. Além disso, a percepção do juiz como um "grande Outro", que define o destino de suas vidas a partir da separação dos pais, também foi verificada e, frente a isso, procuram estratégias para enfrentar estas situações por meio de mecanismos de defesa.

Estes mecanismos, mesmo que usados de forma inconsciente, podem ser definidos como meios importantes encontrados pelas crianças para auxiliá-las a preservar minimamente sua saúde psíquica frente às angústias enfrentadas nestes momentos. Mecanismos como identificação 
projetiva, projeção, o fortalecimento das relações entre irmãos, principalmente nesses momentos e a busca por referenciais maternos e paternos seguros na ausência de pai e mãe, também foram estratégias de enfrentamento encontradas por estas crianças e expressas especialmente por meio da construção de objetos lúdicos.

Nesse sentido, a "Oficina de Sucatas" parece permitir que, com a construção de objetos a partir de materiais recicláveis, seja possível a busca de sentido sobre seus conflitos e lhes revele significados importantes para a elaboração dos sentimentos vivenciados e enfrentamento das situações, permitindo assim a associação com a teoria de Melanie Klein acerca da importância do brincar e do brinquedo.

Sabe-se que o divórcio acarreta consequências não apenas para o casal, mas pode envolver também os filhos. Regressão, agressividade, alienação parental, abandono afetivo, afastamento ou ausência de um dos genitores foram as principais consequências constatadas nas crianças que participaram da presente pesquisa e que, além de terem sido comprovadas por meio de suas falas, também foram observadas em seus comportamentos e nos objetos lúdicos construídos.

Sendo assim, as "Oficinas de Parentalidade" buscam resgatar a parentalidade nesses genitores que, embora feridos com o processo do divórcio e todas as suas consequências, possam compreender que somente eles possuem o poder de determinar o melhor para seus próprios filhos, principalmente quando crianças. Espera-se também que possam entender que o empoderamento de suas funções parentais, auxiliadas por questões como as tratadas nas "Oficinas", possam colaborar para buscar dentro de si mesmos o real sentido de exercer a parentalidade saudável de fato, mesmo na ausência da conjugalidade.

As "Oficinas de Crianças" demonstraram ser um espaço acolhedor e fortalecido para que os sentimentos vivenciados pelas crianças com pais neste processo pudessem ser minimamente elaborados por meio das atividades realizadas, principalmente na construção dos objetos na "Oficina de Sucatas", enfatizando o que Melanie Klein afirma acerca da importância do brincar para a criança, lhe permitindo a elaboração de sentimentos angustiantes por um ato que é naturalmente realizado por elas.

\section{Referências}

AFONSO, T.; SILVA, S. S. D. C., PONTES, F. A. R.; KOLLER, S. H. O uso do diário de campo na inserção ecológica em uma família de uma comunidade ribeirinha amazônica. Psicologia \& Sociedade, Belo Horizonte, v. 27, n. 1, p. 131141, 2015. Doi: http://dx.doi.org/10.1590/1807$03102015 \mathrm{v} 27 \mathrm{n} 1 \mathrm{p} 131$

ARPINI, D. M.; CÚNICO, S. D.; ALVES, A. P. Paternidade: o ponto de vista de profissionais que atuam em varas de família. Pensando Famílias, Porto Alegre, v. 20 n. 1 p. 29-42, 2016. Disponível em: https://bit.ly/2TbWSna. Acesso em: 13 out. 2019.

AZAMBUJA, M. R. F.; LARRATÉA, R. V.; FILIPOUSKI, G. R. Guarda compartilhada: a justiça pode ajudar os filhos a ter pai e mãe? In: SOUZA, I. M. C. C. (coord.). Parentalidade: análise psicojurídica. Curitiba: Juruá, 2009. p. 69-99.

BARDIN, L. Análise de conteúdo. Lisboa: Edições 70, 2011.

BORDONI, J. D. A.; TONET, L. As oficinas de pais e filhos como instrumento para coibir a alienação parental. Themis: Revista da Esmec, Fortaleza, v. 14, p. 105-129, 2016. Disponível em: https://bit. 1y/363deDS. Acesso em: 2 out. 2018.

BRAGA, J. C. O.; FUKS, B. B. Indenização por abandono afetivo: a judicialização do afeto. Tempo Psicanalítico, Rio de Janeiro, v. 45, n. 2, p. 303321, 2013. Disponível em: https://bit.ly/3dS0C52. Acesso em: 2 out. 2018.

BRITO, L. M. T. Família pós-divórcio: a visão dos filhos. Psicologia: Ciência e Profissão, Brasília, v. 27, n. 1, p. 32-45, 2007. Disponível em: https://bit. ly/3cBFCQ0. Acesso em: 2 out. 2018.

CLARKE, J. O melhor dos dois ninhos. Blumenau: Todolivro, 2012. 
CONSELHO NACIONAL DE JUSTIÇA. Oficina de pais e filhos: cartilha do instrutor. Brasília: CNJ, 2016. Disponível em: https://bit.ly/2WDLbYD. Acesso em: 2 out. 2018.

CONSELHO NACIONAL DE JUSTIÇA. Turminha do Enzo: meus pais não moram mais juntos. E agora? Brasília: CNJ, 2015. Disponível em: https://bit.ly/3cEpD3C. Acesso em: 2 out. 2018.

COSTA, D. A. O.; GOMES, F. J. D. O afeto nas relações de pais e filhos e suas consequências em caso de omissão na vida de um filho. ETIC: Encontro de Iniciação Científica, Presidente Prudente, v. 13, n. 13, p. 15-17, 2017. Disponível em: https://bit. ly/2WBfDlV. Acesso em: 2 out. 2018.

COSTA, T. Psicanálise com crianças. Rio de Janeiro: Jorge Zahar, 2008.

CRUZ, D. C. M.; SANTANA, E. C.; BARBOSA, L. P.; SILVA, S. Q. C.;SILVA, S. R. S.; BARBOSA, V. L. Divórcio dos pais: até que ponto isso interfere negativamente nos filhos que estão em fase de desenvolvimento. Cadernos de Graduação: Ciências Humanas e Sociais, Aracaju, v. 1, n. 17, p. 129-134, 2013. Disponível em: https://bit. 1y/2y5sCTw. Acesso em: 2 out. 2018.

FÉRES-CARNEIRO, T.; MAGALHÃES, A. S. A parentalidade nas múltiplas configurações familiares contemporâneas. In: MOREIRA, L. V. C.; RABINOVICH, E. P. (org.). Família $e$ parentalidade: olhares da psicologia e da história. Curitiba: Juruá, 2011. p. 117-134.

FERREIRA, L. J. C. A alienação parental e as consequências sociais e jurídicas para as crianças e os adolescentes. 2015. Trabalho de Conclusão de Curso (Graduação em Direito) - Universidade Tiradentes, Aracaju, 2015.

GOLDSMID, R.; FÉRES-CARNEIRO, T. Relação fraterna: constituição do sujeito e formação do laço social. Psicologia USP, São Paulo, v. 22, n. 4, p. 771-788, 2011. Doi: http://dx.doi.org/10.1590/ S0103-65642011005000031

GRIGORIEFF, A. G.; NÜSKE, J. P. F. Convivência parental: a qualidade das vivências primordiais na constituição psíquica. Diaphora: Revista da Sociedade de Psicologia do Rio Grande do Sul, Porto Alegre, v. 15, n. 2, p. 8-12, 2015. Disponível em: https://bit.ly/365D5Ld. Acesso em: 2 out. 2018.
KLEIN, M. A psicanálise de crianças. Rio de Janeiro: Imago, 1997.

LAPLANCHE, J.; PONTALIS, J. B. L. Vocabulário da psicanálise. São Paulo: Martins Fontes, 2016.

LEITE, D. E. M.; OLIVEIRA NETA, M. R. Síndrome da alienação parental-SAP: o resultado de uma guerra familiar. Direito \& Realidade, Monte Carmelo, v. 4, n. 2, p. 46-71, 2016. Disponível em: https://bit.ly/365Ya8p. Acesso em: 13 out. 2019.

OLIVEIRA, J. L. A. P.; CREPALDI, M. A. Relação entre o pai e os filhos após o divórcio: revisão integrativa da literatura. Actualidades en Psicología, Lisboa, v. 32, n. 124, p. 91-109. 2018. Doi: https://doi.org/10.15517/ap.v32i124.29021

PEREIRA, M. C.; LIRA, P. P. B.; PEDROSA, M. I. Observando brincadeiras e conversando com crianças sobre família. In: MOREIRA, L. V. C.; RABINOVICH; E. P. (org.). Família e parentalidade: olhares da psicologia e da história. Curitiba: Juruá, 2011. p. 41-62.

SANTOS, E. P.; CRUZ, D. C. M.; SANTANA, E. C. de; BARBOSA, L. P.; CRUZ SILVA, S. Q. da; SILVA, S. R. S.; BARBOSA, V. L. Divórcio dos pais: até que ponto isso interfere negativamente nos filhos que estão em fase de desenvolvimento. Cadernos de Graduação: Ciências Humanas e Sociais-UNIT, Aracaju, v. 1, n. 3, p. 124-134, 2013.

SANTOS, M. M. S. Os efeitos do divórcio na família com filhos pequenos. 2013. https://bit.ly/3cF1idQ. Disponível em: Acesso em: 13 out. 2019.

SANTOS, M. R. R. O sofrimento da criança na vivência da disputa de guarda no contexto da justiça. Revista Portuguesa de Pedagogia, Coimbra, v. 48, n. 1, p. 25-37, 2014. Doi: http:// dx.doi.org/10.14195/1647-8614_48-1_2

SCHNEEBELI, F. C. F.; MENANDRO, M. C. S. Com quem as crianças ficarão? Representações sociais da guarda dos filhos após a separação conjugal. Psicologia \& Sociedade, Belo Horizonte, v. 26, n. 1, p. 175-184, 2014.

SILVA, A. H.; FOSSÁ, M. I. T. Análise de conteúdo: exemplo de aplicação da técnica para análise de dados qualitativos.Qualit@s Revista Eletrônica, Campina Grande, v. 16, n. 1 p. 1-14, 2015. Disponível em: https://bit.ly/2LAZxmg. Acesso em: 2 out. 2018. 
SILVA, D. F. A criança fala ao brincar. In: CONGRESSO DE PESQUISA E EXTENSÃO DA FACULDADE DA SERRA GAÚCHA, 3., 2015, Caxias do Sul. Anais [...]. Caxias do Sul: Faculdade da Serra Gaúcha, 2015. v. 3, n. 3, p. 1057-1066. Disponível em: https://bit.ly/2WA7JcB. Acesso em: 2 out. 2018.

SILVA, L. M.; SOUZA ARAGÃO, A.; MORAIS SILVA, L. C.C.; JULIÃO, C. H.; DE LAVOR, M. D. D.; OLIVEIRA CHAGAS, L. M.; GOMES, L. C. S. Oficinas de parentalidade. Participação, Brasília, n. 27, p. 18-26, 2015. Disponível em: https://bit.ly/3dShGYS. Acesso em: 2 out. 2018.

SOUSA, P. A.; ANDRADE, E. P.; ANDRADE, E. P. O brincar na perícia judicial: entre o nãodito e o melhor interesse da criança. ENCONTRO INTERNACIONAL DE FORMAÇÃO DE PROFESSORES, 9., 2016, Aracaju. Anais [...]. Aracaju: Universidade Tiradentes, 2016. v. 9, p. 1-10. Disponível em: https://bit.ly/2WCkF1F. Acesso em: 2 out. 2018.

SOUZA, A. S. L. Existe um lugar para os pais reais: reflexões sobre o lugar dos pais e do analista real na psicanálise de orientação kleiniana. Estilos da Clinica, São Paulo, v. 17, n. 2, p. 278-289, 2012. Disponível em: https://bit.ly/2ZbN3cG. Acesso em: 2 out. 2018.

SOUZA, A. S. L. Melanie Klein e o brincar levado a sério: rumo à possibilidade de análise com crianças. In: GUELLER, A. S.; SOUZA, A. S. L. (org.). Psicanálise com crianças: perspectivas teórico-clínicas. São Paulo: Casa do Psicólogo, 2008. p. 123-134.

SOUZA, A. S. L. Reflexões sobre a transferência na análise de crianças: o enfoque Kleiniano. In: GULlER, A. S.; SOUZA, A. S. L. (org.). Psicanálise com crianças: perspectivas teóricoclínicas. 2. ed. São Paulo https://bit.ly/2WBfDIV: Casa do Psicólogo, 2008. p. 189-200.

TURATO, E. R. Tratado da metodologia da pesquisa clínico-qualitativa. Rio de Janeiro: Vozes, 2011. 
Abreu, C. D.; Silva, L. D. L.; Silva, L. M. 